\title{
Preliminary results of official influenza and acute respiratory infection surveillance in two towns of Burkina Faso, 2013-2015
}

Tani Sagna ${ }^{14^{*}}$, Abdoul Kader Ilboudo ${ }^{1}$, Carine Wandaogo ${ }^{2}$, Assana Cissé ${ }^{1}$, Moussa Sana $^{2}$, Dieudonné Tialla ${ }^{1}$, Armel Moumouni Sanou', David J. Muscatello ${ }^{3}$ and Zékiba Tarnagda'

\begin{abstract}
Background: In 2010, influenza, influenza-like illness (ILI) and acute respiratory infection (ARI) surveillance was established by the government of Burkina Faso. We provide preliminary descriptive results from this surveillance activity.

Methods: The study period was 2013 through 2015. Two primary healthcare facilities in Bobo-Dioulasso district reported ILI in outpatients. Influenza virology, using reverse transcription-polymerase chain reaction (rRT-PCR), was available for a proportion of ILI patients. One hospital, in the capital Ouagadougou, reported ARI in both outpatients and inpatients (hospitalized). Inpatients admitted with ARI were considered severe ARI (SARI). We estimated the proportion of primary care outpatient visits that were ILI, and the proportion of those that were due to influenza, by age. We estimated the proportion of hospital outpatient visits that were ARI and the proportion of those that were SARI, by age.
\end{abstract}

Results: Among combined outpatient visits in the Bobo-Dioulasso facilities, 19.6\% were for ILI. One half (49.9\%) of outpatient visits in infants and $30.9 \%$ in 1-4 year-olds were ILI. Among ILI outpatient visits $14.8 \%$ were due to influenza virus and, of these, 58.5\% were type A and $41.5 \%$ type B. At the Ouagadougou hospital, $6.7 \%$ of outpatient visits were ARI, and $22.3 \%$ of those were SARI. The highest proportions of ARI were among infants (19. $8 \%$ ) and $1-4$ year-olds (16.0\%). The proportion of ARI that was SARI was highest among $\geq 15$ year-olds (31.5\%) followed by 1-4 year-olds (22.4\%). Overall, $4.1 \%$ of SARI patients died.

Conclusions: These preliminary data indicate the importance of respiratory infections among health care attendances in Burkina Faso, and influenza may be an important contributor to these.

Keywords: Influenza, Burden, Influenza-like illness, Severe acute respiratory infections, Burkina Faso

\section{Background}

According to the World Health Organization (WHO), seasonal influenza in humans is estimated to result annually in 3 to 5 million cases of severe illness and 290,000 to 650,000 deaths worldwide [1]. Among children, one in 10 hospitalizations for respiratory illness

\footnotetext{
* Correspondence: stanilinda@gmail.com

${ }^{1}$ Institut de Recherche en Sciences de la Santé (IRSS), Bobo-Dioulasso, Burkina Faso

${ }^{4}$ National Influenza Reference Laboratory, Unit of epidemic-prone diseases, emerging diseases and zoonoses, Department of Biomedical / Public health, Institute of research in health sciences, Bobo-Dioulasso 01BP545, Burkina Faso

Full list of author information is available at the end of the article
}

are estimated to be associated with influenza globally [2].

Burkina Faso lacks information on the epidemiology and burden of human influenza. In 2010, government sentinel surveillance for influenza commenced following the occurrence of pandemic influenza globally in 2009 . Initial surveillance results confirmed the presence of circulating human influenza in the country. From 2010 to 2016, about 600 clinical swabs from all sites were analyzed per year by the Burkina Faso National Influenza Reference Laboratory (NIRL). During 2010-2012, the NIRL found that $6.6 \%$ of swabs collected from patients

(C) The Author(s). 2018 Open Access This article is distributed under the terms of the Creative Commons Attribution 4.0 International License (http://creativecommons.org/licenses/by/4.0/), which permits unrestricted use, distribution, and reproduction in any medium, provided you give appropriate credit to the original author(s) and the source, provide a link to the Creative Commons license, and indicate if changes were made. The Creative Commons Public Domain Dedication waiver (http://creativecommons.org/publicdomain/zero/1.0/) applies to the data made available in this article, unless otherwise stated. 
with influenza-like illness (ILI) were positive for influenza by virology [3].

We used selected influenza and respiratory infection surveillance sites that provided good data completeness to provide preliminary estimates of the proportional contribution of influenza-like illness, influenza and acute respiratory infections (ARI) to outpatient visits and hospitalizations for Burkina Faso.

\section{Methods}

The study period was 2013 through 2015. The surveillance sites chosen for this study were selected due to completeness of reporting and our ability to access their health-care data. Health workers at the sites showed strong motivation in participating in this surveillance. The two cities targeted for this study are Ouagadougou and Bobo-Dioulasso. Bobo-Dioulasso is situated in the southwest of the country, some $350 \mathrm{~km}$ from the capital, Ouagadougou [4]. Public health care is organized into three levels; primary, secondary and tertiary, by the national Ministry of Health $(\mathrm{MoH})$. In Ouagadougou there are five sanitary Districts (Bogodogo, Baskuy, Boulmigou, Nongr-Massom, Sig-Nonghin). Bobo-Dioulasso has two sanitary districts (Dafra and Dô). The two targeted ILI surveillance health centres provide primary care. Bolomakoté health centre is in Dafra District and Colsama health centre is in Dô District. We selected these centres due to their accessibility and the motivation of health workers in this surveillance. Secondary care services receive referrals from primary care health centres. The ARI surveillance site, Bogodogo District hospital, in Ouagadougou, provides secondary level care. Tertiary level care is provided by the national hospital center in Ouagadougou, which offers the highest reference level for specialized care [5].

Since 2010, active surveillance for ILI has been conducted at the two primary health care facilities. We regularly analyze oropharyngeal specimens for influenza screening from these sites. ILI was defined according to the World Health organization case definition: axillary temperature $\geq$ $38{ }^{\circ} \mathrm{C}$, cough or sore throat and difficulty breathing within the last 10 days [6].

Real-time reverse transcription-polymerase chain reaction assay (rRT-PCR) was performed weekly only for specimens from the Bobo-Dioulasso sites. Respiratory specimens (oropharyngeal swabs) were collected from the first three patients meeting the ILI case definition during Monday to Thursday each week. Patients taking antivirals prior to presentation were excluded. We performed rRT-PCR using primers and probes according to the United States Centers for Disease Control and Prevention (US-CDC) protocol [7].

To estimate the proportion of ILI occurring in outpatient visits, we retrospectively analyzed combined surveillance data recorded during the period 2013 to 2015 from the two
Bobo-Dioulasso health facilities. Age-specific proportions of total outpatient visits attributable to ILI were calculated, as were the annual and total proportion of ILI outpatient visits positive for influenza, and the proportion of influenza positive cases that were positive for influenza type A or B. This was done for persons of all ages and for the following age groups: $<1,1-4,5-14, \geq 15$ years.

Bogodogo health facility in Ouagadougou provided data on ARI outpatient visits, and hospitalized ARI only. We defined ARI requiring hospitalization as severe ARI (SARI). ARI was identified by medical record review. Respiratory sampling for acute respiratory infections only commenced at Bogodogo in 2014 and is not yet suitable for surveillance reporting. Medical records in Bogodogo are recorded in paper log books. This hospital has generally good and consistent data recording. Diagnoses are written in the logs and are not coded to a disease classification. We selected the following diagnosis groups as being ARI: rhinopharyngitis, (broncho)pneumonia, bronchitis, acute bronchiolitis, and other acute respiratory infections. At this site, we estimated the proportions of total outpatient visits that were ARI, the proportion of ARI that was SARI, and the hospital case fatality proportion among SARI.

\section{Results}

Among 134,869 total outpatient visits in the two Bobo-Dioulasso primary care facilities during 2013 through 2015, 26,458 (19.6\%) were for ILI. The ILI proportion decreased with increasing age, and $49.9 \%$ of children aged < 1 year presented with ILI (Table 1).

Among the 26,458 ILI outpatient visits over the study period, rRT-PCR was performed for 1392, of which, 207 (14.9\%) were positive for influenza. Among confirmed influenza ILI visits, $58.5 \%$ were type A and $41.5 \%$ were type B. The proportion of type B did not vary substantially across each year (Table 2).

Figure 1 shows the trend in the proportion of each year's ILI outpatient visits that occurred in each month from 2013 to 2015 for Bolomakoté and Colsama health centres combined. The proportion of virologically tested ILI visits that were positive for influenza are also shown. Peaks in ILI

Table 1 Influenza-like illness (ILI) and total outpatient visits, two Bobo-Dioulasso facilities, by age, 2013-2015

\begin{tabular}{|c|c|c|c|c|c|}
\hline \multirow[t]{2}{*}{ Type of visit } & \multicolumn{5}{|c|}{ Age group (years) } \\
\hline & $\begin{array}{l}<1 \\
\text { Number } \\
(\%)\end{array}$ & $\begin{array}{l}1-4 \\
\text { Number } \\
(\%)\end{array}$ & $\begin{array}{l}\text { 5-14 } \\
\text { Number } \\
(\%)\end{array}$ & $\begin{array}{l}\geq 15 \\
\text { Number } \\
(\%)\end{array}$ & $\begin{array}{l}\text { All ages } \\
\text { Number } \\
\text { (\%) }\end{array}$ \\
\hline ILI & $\begin{array}{l}6146 \\
(49.9 \%)\end{array}$ & $\begin{array}{l}8998 \\
(30.9 \%)\end{array}$ & $\begin{array}{l}3942 \\
(15.4 \%)\end{array}$ & $\begin{array}{l}7372 \\
(10.9 \%)\end{array}$ & $\begin{array}{l}26,458 \\
(19.6 \%)\end{array}$ \\
\hline $\begin{array}{l}\text { All } \\
\text { outpatient } \\
\text { visits }\end{array}$ & $\begin{array}{l}12,322 \\
(100.0 \%)\end{array}$ & $\begin{array}{l}29,163 \\
(100.0 \%)\end{array}$ & $\begin{array}{l}25,579 \\
(100.0 \%)\end{array}$ & $\begin{array}{l}67,805 \\
(100.0 \%)\end{array}$ & $\begin{array}{l}134,869 \\
(100.0 \%)\end{array}$ \\
\hline
\end{tabular}


Table 2 Influenza A and B among ILI outpatient visits with influenza virology, Bobo-Dioulasso facilties, Burkina Faso 20132015

\begin{tabular}{lllll}
\hline Influenza type & Year & & & \\
\cline { 2 - 5 } & 2013 & 2014 & 2015 & $2013-2015$ \\
& Number (\%) & Number (\%) & Number (\%) & Number (\%) \\
\hline Influenza A & $61(59.2 \%)$ & $44(56.4 \%)$ & $16(61.5 \%)$ & $121(58.5 \%)$ \\
Influenza B & $42(40.8 \%)$ & $34(43.6 \%)$ & $10(38.5 \%)$ & $86(41.5 \%)$ \\
Total influenza & $103(100.0 \%)$ & $78(100.0 \%)$ & $26(100.0 \%)$ & $207(100.0 \%)$ \\
\hline
\end{tabular}

sometimes, but not always, corresponded to peaks in the proportion positive for influenza. Peaks in influenza occurred in the early months of each year, but other peaks also occurred as well as some periods of several months with sustained influenza activity.

During the study period, there were 115,655 outpatient visits to the Bogodogo facility, excluding medical records from July 2014 which could not be found. Among these, 7759 (6.7\%) were ARI. The highest proportion of outpatient visits that were ARI was among infants (19.8\%) followed by 1-4 year-olds (16.0\%) (Table 3$)$.

Of the 7759 ARI visits, 1727 (22.3\%) were hospitalized (SARI). The proportion of ARI that was SARI was highest among persons aged $\geq 15$ years $(31.5 \%)$ followed by $1-4$ year olds (22.4\%) (Table 3$)$.

Among SARI patients, the hospital case fatality proportion was $4.1 \%$. The case fatality proportion was highest among infants (6.6\%) and lowest among 1-4 year-olds (1.4\%) (Table 4).

\section{Discussion}

During 2013 through 2015, influenza-like illness (ILI) was very common among patients presenting for outpatient visits in the two Bobo-Dioulasso facilities, with one in five experiencing ILI. ILI explained half of all visits in infants and almost one third of visits among children aged 1-4 years. Influenza accounted for around $15 \%$ of ILI outpatient visits. Among influenza ILI visits, influenza A accounted for around 59\%. Overall, ARI accounted for around 7\% of all outpatient presentations to Bogodogo district hospital but accounted for one in 5 presentations among infants and 16\% among $1-4$ year-olds. Just over one in five ARI presentations required hospitalization (SARI) and the proportion hospitalized was highest among patients aged 15 years and over - almost one third. Four per cent of SARI overall was fatal (in hospital), with a slightly higher proportion of fatalities among infants, over 1 in 20. The timing of ILI and ARI varied throughout the year, with unclear seasonality, although incidence appeared to be lowest during the middle of the year in the rainy season of Burkina Faso.

The proportion of ILI positive for influenza that we observed was similar to the proportion of $13 \%$ in Southwestern China during 2011-2015 using a similar case definition and CDC testing protocols [8]. Broadly similar proportions were found in Uganda, in 2016, with 13\% [9]; in Niger during 2009 to 2013, with 12\% [10], and Ghana during 2013 to 2015, with 18\% [11]. Far higher proportions, between 28 and $37 \%$ were reported in Tunisia during 2013 to 2015 [12].

The seasonality of influenza during our 3 year study period was not clear, and data from additional years are needed to better identify seasonality. There is little influenza seasonality data for African regions. In Morocco, influenza peaked during the winter months of October through April [13]. In Nigeria and Niger, influenza peaked in February [10, 14]. In Ghana, cases increased in each of the two rainy seasons starting in May and August [15].

In our study, $6.7 \%$ of outpatient visits to Ouagadougou hospital were ARI. In Reunion, the rate was greater, about $11.9 \%$, possibly due to the severe influenza season in that year (2016) [16]. We found a high proportion of hospital outpatient visits among children aged $<5$ years were ARI and a high proportion of those required hospitalization. In 2015, Diene Sarr et al. in Senegal found that influenza was most frequent among children aged less than 24 months [17]. In China, among < 5 year-olds, children aged 6 months to 4 years experienced the highest rates of influenza-associated ILI [18]. Active surveillance in several developed and developing 
Table 3 (Severe) acute respiratory infections (ARI/SARI) among outpatient visits, by age, Bogodogo facility, 2013-2015ª

\begin{tabular}{llllll}
\hline Category & \multicolumn{5}{l}{ Age group (years) } \\
\cline { 2 - 6 } & $<1$ & $1-4$ & $5-14$ & $\geq 15$ & All ages \\
& Number & Number & $\begin{array}{l}\text { Number } \\
(\%)\end{array}$ & $\begin{array}{l}\text { Number } \\
(\%)\end{array}$ & $\begin{array}{l}\text { Number } \\
(\%)\end{array}$ \\
\hline ARI & 1769 & 1968 & $725(5.8 \%)$ & 3297 & 7759 \\
& $(19.8 \%)$ & $(16.0 \%)$ & & $(4.0 \%)$ & $(6.7 \%)$ \\
SARI $^{\text {b }}$ & 136 & 441 & 112 & 1038 & 1727 \\
& $(7.7 \%)$ & $(22.4 \%)$ & $(15.4 \%)$ & $(31.5 \%)$ & $(22.3 \%)$ \\
Outpatients & 8945 & 12,262 & 12,448 & 82,000 & 115,655 \\
& $(100.0 \%)$ & $(100.0 \%)$ & $(100.0 \%)$ & $(100.0 \%)$ & $(100.0 \%)$ \\
\hline
\end{tabular}

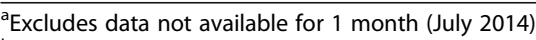

${ }^{\mathrm{b}}$ The denominator for SARI is ARI

countries found picornaviruses (rhinovirus or enteroviruses), followed by influenza, were most commonly found in medically-attended and hospitalised children with ILI who were otherwise healthy [19]. In Ghana, the highest incidence rate of SARI was among children aged $<5$ years [11]. A US study found that $10 \%$ of all children and $4 \%$ of the population aged $<65$ years sought outpatient care for respiratory illness attributable to influenza annually [20]. Several other studies also revealed the involvement of ARI on outpatient visit among children [21-23]. These results highlight the strong involvement of respiratory infections in health-care attendance. While we were not able to estimate the age-specific contribution of influenza to either ILI or ARI, these international data suggest influenza is likely to be an important preventable cause of illness in young children in Burkina Faso. Immunization of children has already demonstrated it effectiveness against influenza infection [24-26]. Thus, free vaccination against influenza in children aged under 5 years may be an important preventive strategy in Burkina Faso.

We determined that case fatality proportion for ARI was highest among infants (6.6\%) and lowest among 14 year-olds (1.4\%). The average case fatality proportion was $4.1 \%$ among SARI cases. This is consistent with other studies demonstrating the importance of ARI as a cause of hospitalization and death $[9,18,27]$.

Table 4 Severe acute respiratory infection deaths, by age, Bogodogo facility, 2013-2015

\begin{tabular}{lllll}
\hline Category & \multicolumn{4}{l}{ Age group (years) } \\
\cline { 2 - 5 } & $\begin{array}{l}\text { Number } \\
(\%)\end{array}$ & $\begin{array}{l}1-4 \\
\text { Number } \\
(\%)\end{array}$ & $\begin{array}{l}\geq 5 \\
\text { Number (\%) }\end{array}$ & $\begin{array}{l}\text { All ages } \\
\text { Number (\%) }\end{array}$ \\
\hline $\begin{array}{l}\text { SARI deceased } \\
\text { cases }\end{array}$ & $9(6.6 \%)$ & $6(1.4 \%)$ & $55(4.8 \%)$ & $70(4.1 \%)$ \\
All SARI & 136 & $441(100.0 \%)$ & $1150(100.0 \%)$ & $1727(100.0 \%)$ \\
& $(100.0 \%)$ & & & \\
\hline
\end{tabular}

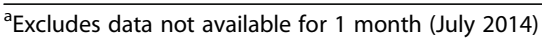

Aside from the human disease burden of respiratory tract infection, there are economic [28-30], and social costs [31]. Thus, prevention of respiratory infections should be a priority.

There are substantial challenges to influenza surveillance in Burkina Faso. The quality of medical record keeping practices in health facilities is variable, and paper-based records are still the norm. Some medical records were unable to be located. Population catchment sizes for the health care facilities were unable to be estimated, and thus population rates were not able to be calculated.

\section{Conclusion}

These preliminary influenza data indicate the strong involvement of respiratory infections among health care attendances in Burkina Faso, particularly among young children. Many require hospitalization and more than 1 in 20 infections in infants are fatal. Influenza appears to account for a substantial proportion of acute respiratory infections, although not the majority. We have demonstrated the feasibility of developing stronger influenza surveillance in Burkina Faso. These data will support the implementation of an influenza prevention and vaccine policy, particularly for young children.

\section{Abbreviations \\ ARI: Acute respiratory infection; ILI: Influenza-like illness; $\mathrm{MoH}$ : Ministry of Health; NIRL: National influenza reference laboratory; rRT-PCR: Real time reverse transcription-polymerase chain reaction; SARI: Severe acute respiratory infection; US-CDC: United States Centers for Disease Control and Prevention; WHO: World Health Organization}

\section{Availability of data and materials}

The datasets used and/or analysed during the current study are available from the corresponding author on reasonable request.

\section{Authors' contributions}

TS and ZT conceived the study. TS, ZT and DJM participated in its design and edited the manuscript. TS, AKI, CW, MS, DT and AMS collected data and edited the manuscript. TS and AC tested specimens and contributed to the manuscript. All authors read and approved the final manuscript.

\section{Ethics approval and consent to participate}

According to national ethics committee (Comité d'éthique pour la recherche en Santé au Burkina Faso), this protocol do not required ethics approval because it is disease surveillance study. We also retrospectively analyzed surveillance data.

\section{Consent for publication}

Not applicable.

\section{Competing interests}

The authors declare that they have no competing interests.

\section{Publisher's Note}

Springer Nature remains neutral with regard to jurisdictional claims in published maps and institutional affiliations.

\section{Author details}

${ }^{1}$ Institut de Recherche en Sciences de la Santé (IRSS), Bobo-Dioulasso, Burkina Faso. ${ }^{2}$ Ministère de la Santé, Ouagadougou, Burkina Faso. ${ }^{3}$ School of Public Health and Community Medicine, UNSW Sydney, Sydney, Australia. 
${ }^{4}$ National Influenza Reference Laboratory, Unit of epidemic-prone diseases, emerging diseases and zoonoses, Department of Biomedical / Public health, Institute of research in health sciences, Bobo-Dioulasso 01BP545, Burkina Faso.

\section{Received: 1 March 2018 Accepted: 5 July 2018}

Published online: 16 July 2018

\section{References}

1. Iuliano AD, Roguski KM, Chang HH, Muscatello DJ, Palekar R, Tempia S, et al. Lancet. 2018:391:1285-300.

2. Lafond KE, Nair H, Rasooly MH, Valente F, Booy R, Rahman M, et al. Global role and burden of influenza in pediatric respiratory hospitalizations, 1982 2012: a systematic analysis. PLoS Med. 2016;13(3):e1001977.

3. Tarnagda Z, Yougbaré I, Ilboudo AK, Kagoné T, Sanou AM, Cissé A, et al. Sentinel surveillance of influenza in Burkina Faso: identification of circulating strains during 2010-2012. Influenza Other Respir Viruses. 2014:8:524-9.

4. Institut national de la statistique et de la démographie, Burkina Faso. 2006. http://www.insd.bf/n/. Accessed 4 May 2017.

5. Ministère de la santé. Document de Politique Sanitaire Nationale, Burkina Faso. 2000. http://www.sante.gov.bf/index.php?option=com edocman\&view=category\&id=5\&ltemid=1122. Accessed 4 May 2017.

6. World Health Organization. Global epidemiological surveillance standards for influenza. 2013. http://www.who.int/influenza/resources/documents/ WHO_Epidemiological_Influenza_Surveillance_Standards_2014.pdf. Accessed 4 May 2017.

7. World Health Organization. CDC protocol of realtime RTPCR for influenza $A(H 1 N 1)$. 2009. http://www.who.int/csr/resources/publications/ swineflu/CDCRealtimeRTPCR_SwineH1Assay-2009_20090430.pdf. Accessed 4 May 2017.

8. Qi L, Xiong Y, Xiao B, Tang W, Ling H, Long J, et al. Epidemiological and Virological characteristics of influenza in Chongqing, China, 2011-2015. PLoS One. 2016;11:e0167866.

9. Cummings MJ, Bakamutumaho B, Kayiwa J, Byaruhanga T, Owor N, Namagambo B, et al. Epidemiologic and spatiotemporal characterization of influenza and severe acute respiratory infection in Uganda, 2010-2015. Ann Am Thorac Soc. 2016;13:2159-68.

10. Mainassara HB, Lagare A, Tempia S, Sidiki A, Issaka B, Abdou Sidikou B, et al. Influenza sentinel surveillance among patients with influenza-like-illness and severe acute respiratory illness within the framework of the National Reference Laboratory, Niger, 2009-2013. PLoS One. 2015;10:e0133178.

11. Ntiri MP, Duque J, McMorrow ML, Frimpong JA, Parbie P, Badji E, et al. Incidence of medically attended influenza among residents of ShaiOsudoku and Ningo-Prampram districts, Ghana, may 2013 - April 2015. BMC Infect Dis. 2016;16:757.

12. Chlif S, Aissi W, Bettaieb J, Kharroubi G, Nouira M, Yazidi R, et al. Modelling of seasonal influenza and estimation of the burden in Tunisia. East Mediterr Health J. 2016;22:460-7.

13. Barakat A, Ihazmad H, Benkaroum S, Cherkaoui I, Benmamoun A, Youbi M, et al. Influenza surveillance among outpatients and inpatients in Morocco, 1996-2009. PLoS One. 2011;6:e24579.

14. Dalhatu IT, Medina-Marino A, Olsen SJ, Hwang I, Gubio AB, Ekanem EE, et al. Influenza viruses in Nigeria, 2009-2010: results from the first 17 months of a national influenza sentinel surveillance system. J Infect Dis. 2012;206(Suppl 1):121-8

15. Jones AH, Ampofo W, Akuffo R, Doman B, Duplessis C, Amankwa JA, et al. Sentinel surveillance for influenza among severe acute respiratory infection and acute febrile illness inpatients at three hospitals in Ghana. Influenza Other Respir Viruses. 2016;10:367-74.

16. Filleul L, Ranoaritiana DB, Balleydier E, Vandroux D, Ferlay C, Jaffar-Bandjee $M C$, et al. A major impact of the influenza seasonal epidemic on intensive care units, Reunion, April to August 2016. Euro Surveill. 2016;21:47.

17. Diene Sarr F, Niang M, Thiam D, Dia N, Badiane A, Ndao AB, et al. Acute febrile illness and influenza disease burden in a rural cohort dedicated to malaria in Senegal, 2012-2013. PLoS One. 2015:10:e0143999.

18. Zhang T, Zhang J, Hua J, Wang D, Chen L, Ding Y, et al. Influenza-associated outpatient visits among children less than 5 years of age in eastern China, 2011-2014. BMC Infect Dis. 2016;16:267.

19. Taylor S, Lopez P, Weckx L, Borja-Tabora C, Ulloa-Gutierrez R, Lazcano-Ponce $E$, et al. Respiratory viruses and influenza-like illness: epidemiology and outcomes in children aged 6 months to 10 years in a multi-country population sample. J Infect. 2017:74:29-41.

20. Matias G, Haguinet F, Lustig RL, Edelman L, Chowell G, Taylor RJ. Model estimates of the burden of outpatient visits attributable to influenza in the United States. BMC Infect Dis. 2016;16:641.

21. O'Brien MA, Uyeki TM, Shay DK, Thompson WW, Kleinman K, McAdam A, et al. Incidence of outpatient visits and hospitalizations related to influenza in infants and young children. Pediatrics. 2004;113:585-93.

22. Iwane MK, Edwards KM, Szilagyi PG, Walker FJ, Griffin MR, Weinberg GA, et al. Population-based surveillance for hospitalizations associated with respiratory syncytial virus, influenza virus, and parainfluenza viruses among young children. Pediatrics. 2004;113:1758-64.

23. Griffin MR, Walker FJ, Iwane MK, Weinberg GA, Staat MA, Erdman DD, et al. Epidemiology of respiratory infections in young children: insights from the new vaccine surveillance network. Pediatr Infect Dis J. 2004; 23(Suppl 11):188-92.

24. Munoz FM. The impact of influenza in children. Semin Pediatr Infect Dis. 2002;13:72-8.

25. Smit MA, Wang HL, Kim E, Barragan N, Aldrovandi GM, El Amin AN, et al. Influenza vaccine is protective against laboratory-confirmed influenza in obese children. Pediatr Infect Dis J. 2016;35:440-5.

26. Jackson ML, Jackson LA, Kieke B, McClure D, Gaglani M, Murthy K, et al. Incidence of medically attended influenza infection and cases averted by vaccination, 2011/2012 and 2012/2013 influenza seasons. Vaccine. 2015;33:5181-7

27. Guo RN, Zheng HZ, Ou CQ, Huang LQ, Zhou Y, Zhang X, et al. Impact of influenza on outpatient visits, hospitalizations, and deaths by using a time series Poisson generalized additive model. PLoS One. 2016;11:e0149468.

28. Murray MT, Heitkemper E, Jackson O, Neu N, Stone P, Cohen B, et al. Direct costs of acute respiratory infections in a pediatric long-term care facility. Influenza Other Respir Viruses. 2016:10:34-6.

29. Yang J, Jit M, Leung KS, Zheng YM, Feng LZ, Wang LP, et al. The economic burden of influenza-associated outpatient visits and hospitalizations in China: a retrospective survey. Infect Dis Poverty. 2015;4:44.

30. Bhuiyan MU, Luby SP, Alamgir NI, Homaira N, Mamun AA, Khan JA, et al. Economic burden of influenza-associated hospitalizations and outpatient visits in Bangladesh during 2010. Influenza Other Respir Viruses. 2014;8:406-13.

31. McLean HQ, Peterson SH, King JP, Meece JK, Belongia EA. School absenteeism among school-aged children with medically attended acute viral respiratory illness during three influenza seasons, 2012-2013 through 2014-2015. Influenza Other Respir Viruses. 2017:11:220-9.

Ready to submit your research? Choose BMC and benefit from

- fast, convenient online submission

- thorough peer review by experienced researchers in your field

- rapid publication on acceptance

- support for research data, including large and complex data types

- gold Open Access which fosters wider collaboration and increased citations

- maximum visibility for your research: over $100 \mathrm{M}$ website views per year

At BMC, research is always in progress.

Learn more biomedcentral.com/submissions 